1 Pontifícia Universidade Católica de São Paulo (PUC-SP) - São Paulo (SP) Brasil.

sandralassis@hotmail.com

2 Fundação Getulio Vargas (FGV), Escola de Administração de Empresas de São Paulo (Eaesp) - São Paulo (SP) Brasil.

\section{Percepção e hierarquia de riscos de inundação recorrente em área urbana regularizada: uma análise discursiva}

\author{
Risk perception and hierarchy of risks related to recurrent floods in a \\ regularized urban area: a discursive analysis
}

Sandra Luzia Assis da Silva', Mário Henrique da Mata Martins², Mary Jane Paris Spink

RESUMO Este estudo analisou estratégias discursivas adotadas por moradores que vivem em uma área de risco de inundações recorrentes para justificar sua permanência no bairro. Foi baseado em suas percepções, critérios de hierarquização de riscos, ações preventivas e ações de mitigação de riscos. Para tanto, foram analisados trechos de diários de campo e entrevistas semiestruturadas com dois moradores que discordavam sobre o risco de inundações e a necessidade de permanecer no bairro. Os resultados mostram que as dificuldades econômicas de realocação e os princípios morais que impedem alguém de vender sua casa são argumentos usados pelo morador que quer se mudar do bairro. O morador que deseja permanecer no bairro tende a normalizar os riscos e a valorizar os benefícios da região. Os residentes decidem se devem ou não deixar a água entrar em suas casas durante uma enchente e se devem ou não sair de casa durante a estação chuvosa para realizar suas atividades diárias com base em sua organização prévia e apego ao lugar e bens materiais. Conclui-se que as inundações afetam a vida cotidiana dos moradores e envolvem processos de tomada de decisão que precisam ser considerados pelas autoridades públicas na gestão de riscos.

PALAVRAS-CHAVE Linguagem. Percepção. Gestão de risco. Desastres naturais. Inundações.

\begin{abstract}
This study analyzed discursive strategies adopted by residents who live in an area of risk of recurrent flooding to justify their stay in the neighborhood. It was based on their perceptions, risk hierarchisation criteria, preventive actions and risk mitigation actions. For this purpose, excerpts from field diaries and semi-structured interviews with two residents who disagreed about the risk of flooding and the need to stay in the neighborhood were analyzed. Results show that economic difficulties of relocation and the moral principles that prevent someone from selling their house are arguments used by the resident who wants to move from the neighborhood. The resident who wants to stay in the neighborhood tends to normalize the risks and to value the benefits of the region. Residents decide whether or not to let water enter their homes during a flood and whether or not to leave the house during the rainy season to carry out their daily activities based on their prior organization and attachment to the place and material goods. It is concluded that floods affect the daily lives of residents and involve decision-making processes, which need to be considered by the public authorities in risk management.
\end{abstract}

KEYWORDS Language. Perception. Risk management. Natural disasters. Floods. 


\section{Introdução}

As inundações são o desastre natural mais comum em todo o mundo, e seu impacto tende a aumentar em virtude dos efeitos das mudanças populacionais, urbanas e climáticas $^{1-3}$. Esses fenômenos representam perigos imediatos à saúde humana, como ferimentos e afogamentos, e impactos em longo prazo, como os resultantes de enfermidades relacionadas com o contato com água contaminada ${ }^{4-7}$. Por conseguinte, as inundações têm- se configurado cada vez mais como graves problemas de saúde pública, em especial, em países em desenvolvimento como o Brasile, onde o avanço na legislação não foi acompanhado pela garantia da fiscalização e ainda exige a criação de instâncias participativas e ações educativas como medidas complementares ${ }^{9}$.

Considerando essas medidas, estudos recentes têm apontado para a necessidade de promover a resiliência dos membros das comunidades afetadas por inundações por meio de estratégias de participação comunitária para a redução de riscos de desastres perante as autoridades públicas ${ }^{10}$. Embora as medidas de participação pública sejam o meio mais eficaz para promover conhecimento sobre desastres potenciais, reforçar a confiança nas autoridades públicas e encorajar cidadãos a assumir mais responsabilidades na proteção e preparação para desastres, a experiência dos membros da comunidade com riscos e sua confiança ou falta de confiança nas autoridades e especialistas, são os principais fatores que moldam a percepção de risco de membros de uma comunidade, e isso tem sido um desafio à organização de estratégias de ação integrada" ${ }^{11}$.

Por esse motivo, para que a população participe da redução de desastres, é necessário que as autoridades públicas compreendam como os moradores de determinada região percebem os riscos de inundação aos quais estão submetidos $^{\mathbf{1 2}}$, e tal compreensão é considerada a primeira prioridade de ação no Marco de Sendai para a Redução do Risco de Desastres 2015-2030 ${ }^{13}$. Assim, esse procedimento é necessário porque o modo como as pessoas percebem os riscos relacionados com as inundações influenciam diretamente na maneira pela qual compreenderão suas condições de possibilidade para gerenciar esses riscos ${ }^{\mathbf{1 4}}$; e, a partir desse processo é possível alcançar a segunda prioridade do Marco de Sendai, o fortalecimento da governança do risco de desastres para gerenciar o risco de desastres.

Além disso, estudos no âmbito da saúde pública têm mostrado que as formas de priorizar determinados riscos e estratégias de enfrentamento em detrimento de outros estão intimamente relacionadas com a percepção que determinados grupos têm dos riscos aos quais estão submetidos ${ }^{\mathbf{1 5}, \mathbf{1 6}}$. No caso específico das inundações, fatores cognitivos, comportamentais, socioeconômicos, demográficos, geográficos, informacionais e culturais são elementos-chave para determinar os critérios levados em conta, e precisam integrar o processo de análise das percepções e hierarquias dos riscos ${ }^{17}$.

Embora evidentemente necessários, os estudos sobre percepção de riscos e, consequentemente, sobre as formas de priorizar determinadas ações com bases nessas percepções partem de uma concepção realística e naturalizada do mundo: consideram que a variabilidade da percepção social é efeito de interpretações distorcidas da realidade e que a hierarquização se pauta em uma atitude que reflete uma coerência interna ${ }^{18}$. Logo, nessa perspectiva, existiria uma percepção correta dos riscos de inundação e uma forma adequada de hierarquizar riscos. Tal leitura tende a posicionar autoridades públicas e científicas como detentoras do saber sobre riscos; e a população, como grupos que precisam ser conscientizados, o que vai contra o movimento de integração comunitária e valorização do saber local fomentada nas ações de redução de riscos de desastres.

Uma alternativa tem sido proposta no âmbito dos estudos sobre o discurso e as práticas discursivas que visam explorar a heterogeneidade discursiva dos enunciados ${ }^{18,19}$. Uma perspectiva discursiva se justifica porque os 
processos de percepção e hierarquização de riscos fazem uso de determinadas linguagens para falar sobre riscos, as quais, por sua vez, estão atreladas a discursos sobre risco 20-21. Nessa perspectiva, perceber riscos significa produzir múltiplas versões discursivas de um fenômeno, assim como as atitudes que pautam a hierarquização de riscos configuram um posicionamento público a respeito de uma controvérsia ou situação que exige tomada de decisão18. Partir do princípio teórico de que o risco é construído discursivamente permite explorar a interface entre os públicos analisados e os tipos de justificativa que adotam quando produzem ou avaliam argumentos relacionados com o tema de interesse ${ }^{22}$.

Considerando tais condições, o presente estudo analisa estratégias discursivas adotadas por moradores que residem em uma área de risco de inundações recorrentes para justificar sua permanência na área. É baseado em suas percepções dos riscos, as formas como hierarquizam riscos e, consequentemente, as ações de prevenção e preparação que priorizam.

A pesquisa foi desenvolvida no bairro Vila América, em Santo André. De acordo com o Instituto Brasileiro de Geografia e Estatística (IBGE), dados de 2010 com estimativa para 2013, a região é caracterizada como área urbana regularizada totalmente (integrada) e com uma população de 4.518 habitantes, distribuídos em uma área de $0,53 \mathrm{~km}^{2}$, com 1.565 domicílios particulares permanentemente ocupados e, desse total, 88 em área de risco de inundação ${ }^{23}$.

\section{Material e métodos}

Para alcançar os objetivos deste artigo, foi adotada uma estratégia metodológica que contemplou o cruzamento de informações provenientes de duas fontes: 1) diário de campo, produzido a partir de visitas aos atores envolvidos ${ }^{24}$; e 2) entrevista semiestruturada com dois moradores com opiniões distintas a respeito da necessidade de permanência no bairro 25 . Para sistematizar as informações relativas às entrevistas, foram elaborados mapas dialógicos ${ }^{26}$.

A negociação para a primeira inserção no bairro foi intermediada pelo Departamento de Defesa Civil, que indicou como interlocutora uma liderança comunitária. A aproximação com essa liderança possibilitou a compreensão das inundações no local e o entendimento de como os moradores que estão na área de risco lidam com a problemática. A escolha dos interlocutores da pesquisa foi coproduzida em ato, entre a pesquisadora e a líder comunitária, estando, portanto, a reflexividade presente na escolha de dois participantes ${ }^{25}$. O critério de seleção foi entrevistar dois moradores com opiniões distintas a respeito do desejo e da necessidade de permanência no bairro: umé $\mathrm{N}$, morador mais antigo do bairro que, portanto, reside na região desde o início das inundações e deseja permanecer; outro é W, moradora que, embora não resida há muito tempo, é liderança comunitária e foi muito atuante desde sua chegada à região, mas que espera sair do local.

Utilizamos uma letra para substituir os nomes dos participantes, buscando atender ao Código de Ética em Pesquisa 466/12, que enfatiza, entre outras coisas, a proteção dos participantes. A pesquisa foi aprovada pelo Comitê de Ética em Pesquisa da Pontifícia Universidade Católica de São Paulo (CEPPUC/SP), número do parecer 1.403.575.

Sobre o roteiro de entrevista, foram elaboradas algumas perguntas norteadoras sobre a temática do estudo, tais como: 1) Há quanto tempo mora no bairro?; 2) Quando se mudou para o bairro já tinha inundação e, se não tinha, quando começou?; e 3) Como é viver em uma área de inundação? As entrevistas foram agendadas de acordo com a disponibilidade dos moradores e realizadas em locais de suas preferências. Foi iniciada com a apresentação dos objetivos e procedimentos de pesquisa e com a solicitação de assinatura do Termo de Consentimento Livre e Esclarecido (TLCE), sendo explicitadas a confidencialidade, a possibilidade de desistência e a permissão para a gravação. 
Quanto aos procedimentos da análise das informações obtidas nas entrevistas, foram elaborados mapas dialógicos. Elas são ferramentas que dão visibilidade ao processo de análise e ao contexto de coprodução das práticas discursivas. $\mathrm{O}$ processo de análise iniciou-se com duas formas de familiarização com o material discursivo: a Transcrição Sequencial (TS) e a Transcrição Integral (TI). A TS foi a primeira aproximação com o material a ser analisado, feita por intermédio de uma escuta atenta do áudio, por meio da qual se buscou identificar os assuntos abordados, possibilitando assim o agrupamento deles em categorias temáticas para uso no mapa. A seguir, foi realizada a TI do áudio, incluindo todas as falas e expressões utilizadas na entrevista. Ela foi feita de forma literal, preservando o discurso original do contexto de pesquisa, possibilitando a compreensão de quem fala, sobre o que fala e como cada um/a fala ${ }^{26}$. Terminada essa etapa, foram enumeradas as Linhas da transcrição (L), para permitir localizar a fala referida no mapa dialógico e na discussão dos resultados. Utilizamos essa estratégia nas duas entrevistas realizadas, com $\mathrm{W}$ e $\mathrm{N}$, elaborando um mapa dialógico para cada uma delas. Após a elaboração dos dois mapas, foram analisados os temas/categorias comuns aos dois entrevistados, resultando em um terceiro mapa com o conteúdo de cada uma das entrevistas localizado em colunas separadas. Esse mapa possibilitou a análise da convivência dos moradores com as inundações recorrentes na região (quadro 1).

Quadro 1. Mapa dialógico do trecho de uma entrevista com W

\begin{tabular}{|c|c|c|c|}
\hline Posicionamento & $\begin{array}{l}\text { Normalização do risco e a barganha, ou } \\
\text { trade-off }\end{array}$ & Dificuldades de realocação & Princípio moral e legal \\
\hline \multirow[t]{3}{*}{$\begin{array}{l}\text { P: como é viver } \\
\text { em uma área de } \\
\text { inundação? }\end{array}$} & $\begin{array}{l}\text { W: a gente já está acostumado com } 5 \text { ou } \\
6 \text { enchentes e a água entrando um palmo } \\
\text { na minha casa. Eu já estou conformada. } \\
\text { Prefiro isso a desabar tudo. No começo } \\
\text { eu chorei porque entrou um palmo de } \\
\text { água na minha casa. A primeira vez eu } \\
\text { queria ir embora, fiquei } 40 \text { dias longe, } \\
\text { abandonei minha casa, eu não queria vol- } \\
\text { tar porque o susto foi demais, eu nunca } \\
\text { tinha visto aquilo. Só que com o tempo } \\
\text { você vai ficando calejada. Hoje, entrar um } \\
\text { palmo eu já estou até contente }\end{array}$ & & \\
\hline & & $\begin{array}{l}\text { Você olha isso aqui, parece uma cidade } \\
\text { fantasma, um monte de casa abandona- } \\
\text { da. Quem teve condições financeiras foi } \\
\text { embora, mas eu não tenho condições. } \\
\text { Já perdi muito com a chuva de 2011; eu } \\
\text { trabalho aqui, perdi maquinário, perdi } \\
\text { tudo. Eu vou pagar aluguel como? Uma } \\
\text { casa igual a essa, quanto é um aluguel de } \\
\text { uma casa igual a essa? }\end{array}$ & \\
\hline & & & $\begin{array}{l}\text { Comprei a casa, gastei tudo o que tinha e } \\
\text { que não tinha para reformar a casa, e } 40 \\
\text { dias depois eu descobri que dava enchen- } \\
\text { te, no dia do aniversário da minha filha de } \\
7 \text { anos [...] Só que eu não tenho coragem } \\
\text { de vender a casa e desfazer o sonho de } \\
\text { outra pessoa também. Como vou vender? } \\
\text { Vou falar e ninguém vai comprar. }\end{array}$ \\
\hline
\end{tabular}

Fonte: Elaboração própria. 
Após essa etapa, foram selecionados os enunciados que diziam respeito a estratégias discursivas adotadas pelos entrevistados para justificar suas percepções dos riscos de residir em uma área sujeita a inundações e as formas como hierarquizam riscos de inundação e ações de prevenção e preparação. O material foi associado aos diários de campo, aos documentos de domínio público e à literatura científica nas áreas dos estudos sobre discurso e desastres ambientais.

\section{Resultados e discussões}

\section{Argumentos para justificar a permanência na área de risco de inundações}

A pesquisa possibilitou identificar que, segundo as autoridades públicas, é o desejo dos próprios moradores que faz com que eles permaneçam na área de risco. Para a moradora que quer sair, as justificativas são a dificuldades de realocação, de financiamento e questões morais relativas à venda da casa. Por fim, para o morador que deseja permanecer na área de risco, a normalização dos riscos de inundações e exposição dos benefícios da região funcionam como estratégias retóricas para justificar a permanência.

\section{ELES FICAM PORQUE QUEREM}

Os primeiros contatos foram efetuados com o Poder Público. Durante a solicitação de documentos que contivessem informações sobre a problemática das inundações na região, as autoridades públicas do Serviço Municipal de Saneamento Ambiental de Santo André (Semasa) enfatizaram a insistência dos moradores da Vila América em permanecer no local, conforme exposto nessa conversa com a pesquisadora.

É possível a liberação de documentos sobre as inundações da Vila América? (Pesquisadora).
Sim. Mas já vou te adiantar, os moradores da Vila América não são coitadinhos não, eles sabem que estão em área de várzea e que lá enche mesmo. Eles também têm condições econômicas de sair de lá, mas não saem. (Autoridade Pública).

A representante infere que o conhecimento dos moradores de que a região é uma área de várzea e sua condição econômica favorável são suficientes para que saiam da área de inundação. Não encontra, portanto, uma explicação plausível para a permanência dessas pessoas, o que pode levar à compreensão de que, para as autoridades públicas, as pessoas continuam morando nessa área porque querem.

Mas por que você acha que eles não saem? (Pesquisadora).

Alguns não saem porque não querem. Eles esperam indenização do governo, mas o valor é alto porque a região é uma área de classe média. A prefeitura não tem dinheiro para indenizar todas as casas que estão na área de risco. Alguns moradores saíram de lá, abandonaram as casas e foram para outro lugar. (Autoridade Púbica).

O mesmo tipo de estratégia retórica foi identificado em uma análise da cobertura de notícias impressas após o furacão Katrina nos EUA, na qual se constatou que as representações jornalísticas se basearam em dispositivos retóricos e estratégias semânticas cuja construção discursiva teve como resultado a transferência da culpa dos órgãos de governo para as 'vítimas' e 'sobreviventes' do desastre27. A atribuição de responsabilidade e, consequentemente, de culpa à vítima é um recurso comum quando o público-alvo é pobre, seja porque o atribuinte é conservador ${ }^{28}$, seja porque nega sua própria condições de pobreza ${ }^{29}$.

O que se destaca no caso analisado, todavia, é que a questão financeira é sobrepujada por uma questão cultural no processo de atribuição de responsabilidade e culpa: a posição econômica relativamente privilegiada dos moradores da Vila América em relação a outros moradores de áreas 
de risco levanta indignação de segmentos da sociedade que, por não compreenderem as razões da permanência, acabam atribuindo culpa aos afetados por sua própria situação. $O$ ciclo de atribuição de culpa à vítima se reproduz mesmo que em uma classe social relativamente privilegiada. Conforme nos ensina Mary Douglas, geralmente a atribuição de culpa por um evento adverso é feita a alguém ou a um grupo que não é popular entre os demais, como esses moradores ${ }^{30}$.

\section{DIFICULDADES ECONÔMICAS, DE REALOCAC̣ÃO E PRINCÍPIOS MORAIS}

Embora o argumento de atribuição de culpa ao grupo afetado esteja presente no discurso das autoridades públicas, ele é questionado por moradores da região com outros argumentos, como se verifica na fala de $\mathrm{W}$ :

O antigo superintendente da Defesa Civil falou que precisamos sair daqui. Então questionei sobre como comprar uma nova casa. Um carro que a gente perde a gente compra fácil, mas uma casa não. (W)

Mas ele falou para vocês saírem daqui e fazerem o que com a casa? (Pesquisadora).

Ele falou informalmente que uma vez morou em um lugar que dava enchente, mas que, quando cresceu saiu de lá. Então eu falei para ele que não tenho dinheiro para comprar outra casa. (W).

Uma razão significativa para a permanência em áreas de risco de inundação é a dificuldade percebida em mudar para outros lugares. As dificuldades de realocação em situação de inundação foram previamente apontadas em estudos da área com justificativas como a falta de lugar para morar, falta de dinheiro ou ausência de um lugar equivalente para morar ${ }^{31}$. Todas elas são expressas por $\mathrm{W}$ no trecho abaixo.

Isso aqui, parece uma cidade fantasma, um monte de casa abandonada. Quem teve condições financeiras foi embora, mas eu não tenho. Já perdi muito com a chuva de 2011; eu trabalho aqui, perdi maquinário, perdi tudo. Eu vou pagar aluguel como? Uma casa igual a essa, quanto é um aluguel de uma casa igual a essa? (W).

Todavia, embora essas sejam as principais razões apontadas por $\mathrm{W}$ para justificar sua permanência, ela ainda faz uso de um recurso não catalogado na literatura: o princípio moral e legal de informar sobre a situação de inundação para possíveis compradores, o que inviabiliza a venda.

Comprei a casa, gastei tudo o que tinha e que não tinha para reformar, e 40 dias depois eu descobri que dava enchente, no dia do aniversário da minha filha de 7 anos [...] Só que eu não tenho coragem de vender a casa e desfazer o sonho de outra pessoa também. Como vou vender? Vou falar e ninguém vai comprar. (W).

No início de sua narrativa, $\mathrm{W}$ conta a sua primeira experiência com inundação na casa que acabara de comprar e seu desconhecimento sobre o assunto, o que provocou muita dor e sofrimento. Ao final, justifica a razão para não sair da casa em que está: ela não pode fazer com os outros o mesmo que fizeram com ela, que comprou algo sem ter sido informada previamente dos problemas com inundações.

Ao contrário do que ocorre em outros países, o Brasil ainda não adota de maneira sistemática os seguros contra inundação. Embora o entrave inicial à implantação dessas estratégias de transferência de risco tenha sido superado com a abertura ao mercado ressegurador internacional, em 2007, e modelos de seguros para riscos hidrológicos tenham sido desenvolvidos ${ }^{32,33}$, esta ainda não é a prática hegemônica para gerenciar esses eventos no País. Os vendedores são obrigados por lei a informar sobre essas situações, o que geralmente leva ao abandono da compra por parte do interessado, ou cometem atos de má fé, como ocorreu com W.

Além de não achar justo vender sua casa sem informar os compradores das inundações, também informa os compradores das 
casas vizinhas, o que tem gerado conflitos com outros moradores.

Quando vem alguém aqui querendo comprar uma casa eu falo que enche de água uns 2 metros. Já mostrei fotos e vídeos. Alguns vizinhos não gostam, ficam bravos se eu falo que enche. Mas se eu não falo e a pessoa compra, vai ficar com raiva depois. (W).

\section{NORMALIZAC̣ÃO DOS RISCOS E TRADE-OFF}

Nem todos os moradores, no entanto, fazem uso de justificativas negativas para permanecerem no local. $\mathrm{N}$ prefere enfatizar os aspectos positivos de morar na vizinhança em detrimento das inundações que, em seu discurso, tornam-se um evento menor.

Aqui é um local ótimo para viver, está próximo de tudo, é de fácil acesso. Só que nós temos esse problema de encher quando chove. A vida da gente aqui é meio temerária quando chega a época de verão. Fora isso, temos uma ótima vizinhança, são pessoas que vivem há muito tempo aqui. $(\mathrm{N})$

Duas estratégias discursivas utilizadas conjuntamente para justificar a permanência na região foram utilizadas: a normalização do risco e a barganha, ou trade-off. A normalização do risco ocorre quando a exposição a inundações recorrentes por um longo período aumenta a consciência, mas diminui a aversão à inundação: ela se torna um elemento integrado ao cotidiano da vida na comunidade. Com relação à barganha, é um processo no qual os benefícios percebidos de viver na área superam o problema percebido de inundações recorrentes de baixa a média intensidade. Combinado com a normalização do risco, esse processo permite assumir riscos e compromete o potencial para antecipar e adaptar-se a um risco crescente de inundação resultante de alterações climáticas e outras mudanças globais, porque desmotiva os residentes a se engajarem em atividades e a fazerem ajustes que reduzam o risco e aumentem a preparação ${ }^{31}$. Embora tenha sido $\mathrm{N}$ quem faz a normalização e a barganha a respeito dos riscos de inundação, é no discurso de $\mathrm{W}$ que seus efeitos desmotivantes aparecem.

A gente já está acostumado com 5 ou 6 enchentes e a água entrando um palmo na minha casa. Eu já estou conformada. Prefiro isso a desabar tudo. No começo eu chorei porque entrou um palmo de água na minha casa. A primeira vez eu queria ir embora, fiquei 40 dias longe, abandonei minha casa, eu não queria voltar porque o susto foi demais, eu nunca tinha visto aquilo. Só que com o tempo você vai ficando calejada. Hoje, entrar um palmo eu já estou até contente [...]. (W).

Com relação ao uso de recursos retóricos utilizados para justificar a permanência habitacional, é possível identificar que os agentes de governo tendem a culpabilizar os afetados, que W justifica sua permanência por razões financeiras e morais enquanto $\mathrm{N}$ justifica sua permanência em virtude da normalização dos riscos de inundação e dos benefícios de viver na região.

\section{Argumentos para justificar as formas de hierarquizar riscos de inundação}

No presente estudo, duas questões foram fundamentais para a discussão sobre as formas de hierarquizar riscos de inundação: a decisão por deixar a água entrar ou não na residência e a decisão sobre permanecer ou sair de casa em períodos de chuva.

\section{DEIXAR OU NÃO DEIXAR A ÁGUA ENTRAR?}

Com relação à primeira discussão, é lugar comum no campo de estudos sobre clima que manter o tempo do lado de fora é uma função essencial de um edifício em quase qualquer clima. Todavia, em se tratando de inundações, duas estratégias podem ser adotadas: resiliência à inundação ou resistência à inundação. A resiliência à inundação é promovida por formas de construção que controlam o quanto de água entra nos edifícios, o que também é conhecido como wet-proofing. Tais formas 
de construção devem ter a capacidade de se recuperar de inundação com intervenção mínima. A resistência a inundações, por sua vez, também conhecida como dry-proofing, é um processo em que a água é mantida fora do edifício por barreiras ou materiais com elevado nível de resistência à água ${ }^{34}$.

Ambos os casos se referem a construções nas quais houve algum tipo de preparação para resistência a inundações. Os moradores entrevistados adotam as estratégias de deixar a água entrar ou não em casa com base nesses princípios, embora suas casas não tenham sido previamente construídas pensando nessa questão. N, por exemplo, desistiu de tentar conter a força da água que transborda do córrego Guarará e optou por deixar que ela entrasse livremente em sua casa. Houve uma época em que tinha um portão com comporta, mas, em consequência de uma forte chuva, esse portão foi arrancado, e, depois disso, o morador resolveu não mais colocá-lo. $\mathrm{N}$ justifica sua decisão com o seguinte argumento:

Então o senhor deixa a água entrar livremente? (Pesquisadora).

É logico. Para o muro suportar uma altura de 2,20m de água é necessária uma estrutura de concreto como de uma piscina, uma muralha. Não é qualquer muro que vai segurar 2,20m de água com a pressão. A área da minha casa tem de 10 a 11 metros de frente e $20 \mathrm{~m}$ de fundo, não é possível segurar, explodiria o muro. (N).

No processo de justificação de N, ele defende a entrada na água contrapondo-se ao método oposto que poderia prejudicar a estrutura da casa. De fato, estudos na área referiram que a estratégia de $d r y$-proofing deveria ser usada com cautela, pois há limitações físicas quanto à quantidade de água que pode ser mantida do lado de fora, em termos de estabilidade estrutural do edifício, nas formas mais comuns de construções. Há também um risco de inundação repentina por meio de abertura, como janelas ${ }^{34}$. $\mathrm{N}$ faz uso desse argumento para defender a entrada da água na casa, mesmo que ela não tivesse sido previamente construída para isso. Na hierarquização de riscos, a explosão dos muros e o dano estrutural à moradia são mais prejudiciais do que a entrada da água, e ele novamente apresenta outro argumento para isso: a preparação interna de sua moradia.
Eu já tive portão, mas ele caiu inteiro e levou junto a pilastra e a mureta. Desde então não coloquei mais nenhum, somente uma folha para fechar a proprie- dade e dizer que tem alguém morando. As vezes pendo em fazer uma estruturação para suportar, mas a única coisa que faço no momento é manter meus materiais, roupas e utensílios elevados, como você está vendo. Eu coloquei essas estruturas de madeira para mantê-los sempre no alto. Assim quando enche não preciso correr para erguer as coisas. $(\mathrm{N})$.

Já W prefere resistir à força da água utilizando comportas, para que sua casa não seja atingida, e seus pertences, destruídos, toda vez que ocorre uma inundação, mas reconhece que não é a melhor coisa a ser feita em função da força da água.

Eu tenho comporta, e já é a segunda que compro. Também tenho bomba com uma válvula de retenção no esgoto e na água de chuva para que eu possa fechar quando começar a inundar, então ela impede que água veze pela pia da cozinha. Eu só não perdi antes as coisas porque eu tomo esses cuidados. Uso a comporta para tentar diminuir os prejuízos, não quero perder sempre as minhas coisas. É uma loucura segurar a água como a gente faz, o certo seria deixar entrar. Sei que isto está acabando com a casa por causa da pressão da água. Você não tem noção, o chão, as paredes, nem sei explicar, parece que você sente a pressão da casa.

Teve uma vez que a comporta de uma vizinha caiu e foi um efeito sanfona, várias também caíram. A minha comporta aguentou, mas a parede lateral não. Ninguém pode com a força da água, a comporta entorta, embarriga, faz barulho, range, vem para dentro. Não sabemos mais o que fazer. (W).

Mesmo vivenciando os efeitos de impedir a entrada da água em sua residência, $\mathrm{W}$ continua 
a fazê-lo. Ela justifica essa prática em virtude da necessidade de manter os bens materiais de sua residência, as memórias.

É horrível destruir sua casa. Tudo que temos está dentro da casa. Eu perdi minhas lembranças, e ninguém vai devolver minha vida passada, minhas fotos, fita de formatura do pré da minha filha. Por causa dos gastos na reforma da casa em uma das chuvas, quase não puder realizar o casamento da minha filha, tive que vender o carro. (W).

A importância de bens que materializam as memórias após inundações ficou evidente em entrevistas com afetados em comunidade inundada e com um funcionário que trabalhava no apoio após o desastre. Além dos entes queridos, as posses que mais sentiam falta eram fotos de família, heranças de família e lembranças, como presentes que conectavam as vítimas aos antepassados. A perda dessas posses resultou em um processo de sofrimento e luto como aquele experimentado na morte de um ente querido ${ }^{35}$. Logo, para W, perder os bens materiais é risco maior do que o risco de ruptura da estrutura da casa.

\section{QUAL O RISCO DE SAIR DE CASA POR UM TEMPO?}

Conviver com o risco de inundações frequentes fez com que o cotidiano desses moradores da Vila América fosse modificado. $\mathrm{W}$ teve que mudar sua rotina de trabalho, alternando o horário de entrada e saída conforme previsões meteorológicas, assim como viagens, passeios e, principalmente, cirurgias.

Eu tinha que fazer cirurgia e não fiz. O meu marido tinha duas hérnias e necessitava de cirurgia, mas teve que cancelar e esperar o período de chuva passar para realizar. Como ele ia ficar em recuperação dentro de casa dando enchente? E se a gente precisar travar a comporta e erguer tudo? Os móveis são muito pesados e temos que carregá- los quando enche. Uma vez minha cama virou em cima do meu braço e fiquei com um cisto. Tenho que tratar, fazer cirurgia, mas como? Minha filha também se machucou na enchente, ela tinha 10 anos e tirou 9 vértebras da coluna do lugar. $O$ acidente aconteceu quando eu estava de dieta, quando um bebê recém-nascido. (W).

Viver em uma área de riscos de inundação fez com que a vida de $\mathrm{W}$ organizasse sua vida em torno desses eventos. Na hierarquia de riscos, sair de casa para uma cirurgia sequer pode ser cogitado, pois o risco de cancelar a cirurgia é menor do que sofrer os impactos de uma inundação repentina.

$\mathrm{N}$ também deixa de sair nessa época para não correr o risco de ficar ilhado fora de casa por causa da inundação.

Construir muros e comportas melhora a situação, mas não resolve. A região enche no mesmo jeito e ficamos impedidos de sair de casa, ficamos debaixo da água. Como você vai ficar saindo? A pessoa se livrou de ter um certo prejuízo, mas está se privando de sair. O problema é se acontece alguma emergência e você precisa sair. Mas eu não saio quando começa a chover, pois posso correr o risco de não conseguir voltar para casa. (N).

\section{Conclusões}

Considerando que as inundações têm-se configurado cada vez mais como graves problemas de saúde pública no Brasil e buscando atender às prioridades estabelecidas no Marco de Sendai ${ }^{13}$, é necessário que as autoridades públicas compreendam como os moradores de determinada região percebem os riscos de inundação aos quais estão submetidos.

Nessa perspectiva, o presente artigo, no âmbito dos estudos sobre o discurso e as práticas discursivas, buscou analisar estratégias discursivas adotadas por moradores que residem em uma área de risco de inundações recorrentes para justificar sua permanência na área a partir de suas percepções dos riscos, as formas como hierarquizam riscos e, consequentemente, as ações de prevenção e preparação que priorizam. 
Em primeiro lugar, há que destacar que estamos falando de riscos antrópicos, ou seja, aqueles que se tornaram presentes em decorrência de intervenções na paisagem urbana, como obras que resultaram em desvio de córregos e rios ou gargalos resultantes dessas obras. Portanto, em uma perspectiva mais macro, caberia um planejamento que levasse em conta as características geográficas (o córrego, o terreno) e urbanas (a densidade de habitações existentes e já consolidadas) da área. Isso, conforme amplamente discutido no livro 'Viver em áreas de risco'36, requer um planejamento participativo em dialogia com a população afetada. Porém, como mostram os dados desta pesquisa, a tendência dos governantes é de se eximir de responsabilidade, afinal, dizem que 'eles ficam porque querem'.

Em termos discursivos, a controvérsia que assim se instala, entre versões de direitos, acaba por propiciar estratégias de enfrentamento de riscos recorrentes, seja de inundações, como é o caso nesta pesquisa, seja de morar em áreas de risco ${ }^{36}$ : normalizar (riscos que estão sempre presentes e aprendemos a conviver com eles) e/ou enfatizar os trade-off, contrastando benefícios e perdas (no caso de moradias em áreas de risco, literalmente, deixar de ter um teto sobre a cabeça).

A pesquisa possibilitou identificar diversas justificativas para permanência na área de risco de inundações e uma ambivalência entre permanecer e sair. Quanto à moradora que deseja sair da região, identificamos os seguintes argumentos: 1) dificuldades econômicas e de realocação, que, segundo estudos da área, estão relacionadas com a falta de lugar para morar, falta de dinheiro ou ausência de um lugar equivalente para morar ${ }^{31}$; e 2) princípios morais, sendo esta uma justificativa original não encontrada na literatura pesquisada. Em relação ao morador que deseja ficar, a normalização dos riscos de inundações e exposição de benefícios da região funciona como estratégia retórica para justificar a permanência, ou seja, ele prefere enfatizar os aspectos positivos de morar na vizinhança em detrimento das inundações, que, em seu discurso, tornam-se um evento menor. Quanto à posição das autoridades públicas, é o desejo dos próprios moradores que faz com que eles fiquem. Esse posicionamento possibilita uma culpabilização dos moradores por continuarem vivendo em áreas de risco.

A respeito da hierarquia de risco de inundação, duas questões foram fundamentais para compreender a justificativa: 1) a decisão por deixar a água entrar ou não na residência; e 2) a decisão sobre permanecer ou sair de casa em períodos de chuva. No primeiro aspecto, notou-se posicionamentos distintos entre os moradores - enquanto para $\mathrm{N}$ a explosão dos muros e o dano estrutural à moradia é mais prejudicial do que a entrada da água, para $\mathrm{W}$, perder os bens materiais é risco maior do que o risco de ruptura da estrutura da casa. Na segunda questão, houve convergência de opiniões, pois os dois moradores relataram modificações na vida cotidiana em função do risco de inundações, ou seja, eles deixam de realizar tarefas na iminência de um potencial evento. Assim, no processo de hierarquia, o risco da não realização de tarefas é menor do que sofrer os impactos de uma inundação repentina.

Os resultados da pesquisa mostraram que as distintas maneiras de perceber e lidar com os riscos de inundação produzem múltiplas versões discursivas do fenômeno, assim como as atitudes que pautam a hierarquização de riscos configuram um posicionamento público a respeito de uma controvérsia ou situação que exige tomada de decisão. Como desdobramentos da pesquisa, propomos explorar em outros casos o elemento moral como argumento para relação entre permanência ou transferência habitacional.

\section{Colaboradores}

Silva SLA (0000-0002-1290-6542)*, Martins MHM (0000-0002-1370-300X)*e Spink MJP (0000-0003-1672-505X)* contribuíram igualmente para a elaboração do manuscrito.
* Orcid (Open Researcher and Contributor ID). 


\section{Referências}

1. Alderman K, Turner LR, Tong S. Floods and human health: A systematic review. Env. International. 2012; (47):37-47.

2. Doocy S, Daniels A, Murray S, et al. The human impact of floods: a historical review of events 1980-2009 and systematic literature review. PLOS Currents Disast. 2013; (1):1-29.

3. Paterson D, Wright H, Harris PNA. Health risks of flood disasters. Clinical Infectious Diseases. 2018; 67(9):1450-1454

4. Noji E. The Public Health Consequences of Disasters. Prehosp Disaster Med. 2000; 15(4):21-31.

5. Londe L, Conceição RS, Bernardes T, et al. Flood-related leptospirosis outbreaks in Brazil: perspectives for a joint monitoring by health services and disaster monitoring centers. Nat Hazards. 2016; 84(2):1419-1435

6. Saulnier DD, Brolin RK, Von Schreeb J. No calm after the storm: A systematic review of human health following flood and storm disasters. Prehosp Disaster Med. 2017; 32(5):568-579.

7. Saulnier DD, Hanson C, Ir P, et al. The Effect of Seasonal Floods on Health: Analysis of Six Years of National Health Data and Flood Maps. Int. J. Environ. Res. Public Health. 2018; 15(4):665.

8. Freitas CM, Ximenes EF. Enchentes e saúde pública: uma questão na literatura científica recente das causas, consequências e respostas para prevenção e mitigação. Ciênc. Saúde Colet. [internet]. 2012 [acesso em 2019 set 21]; 17(6):1601-1616. Disponível em: http:// dx.doi.org/10.1590/S1413-81232012000600023.

9. Assumpção RF, Séguin E, Kligerman DC, et al. Possíveis contribuições da integração das políticas públicas brasileiras à redução de desastres. Saúde debate [internet]. 2017 [acesso em 2019 jul 13]; 41(esp2):39 49. Disponível em: http://dx.doi.org/10.1590/0103$-11042017 \mathrm{~s} 204$.
10. Mayer B. Curr Envir Health Rpt. Springer Inter. Pub. 2019; (6):167-173

11. Wachinger G, Renn O, Begg C, et al. The risk perception paradox--implications for governance and communication of natural hazards. Risk Analys. 2013 33(6):1049-1065

12. Motoyoshi T. Public perception of flood risk and community-based disaster preparedness. Terra Scientific Publishing Company [internet]. 2006 [acesso em 2019 set 21]; 121-134. Disponível em: http://www.terrapub.co.jp/e-library/nied/pdf/121.pdf.

13. United Nations. Sendai Framework for Disaster Risk Reduction 2015 - 2030. [internet]. 2015. [acesso em 2019 set 21]. Disponível em: https://www.unisdr.org/ files/43291_sendaiframeworkfordrren.pdf.

14. Kellens W, Terpstra T, De Maeyer P. Perception and Communication of Flood Risks: A Systematic Review of Empirical Research. Risk Analysis. 2013; 33(1):24-49.

15. Rhodes T. Risk theory in epidemic times: sex, drugs and the social organisation risk behaviour. Sociol. Health \& Illness. 1997; 19(2):208-227.

16. Rance J, Treloar C, Fraser S, et al. “Don't think I'm going to leave you over it": Accounts of changing hepatitis $\mathrm{C}$ status among couples who inject drugs. Drug and Alcohol Depend. 2017; 173:78-84.

17. Lechowska E. What determines flood risk perception? A review of factors of flood risk perception and relations between its basic elements. Nat Hazards. 2018; 94(3):1341-1366.

18. Wetherell M, Potter J. Mapping the Language of Racism: Discourse and the Legitimation of Exploitation. London; New York: Harvester Wheatsheaf; Columbia University Press; 1992.

19. Potter J. Representing Reality: Discourse, Rhetoric and Social Construction. London: Sage; 1996. 
20. Spink MJP. Trópicos do discurso sobre risco: risco-aventura como metáfora na modernidade tardia. Cad. Saúde Pública [internet]. 2001 [acesso em 2018 jul 13]; 17(6):1277-1311. Disponível em: http://dx.doi. org/10.1590/S0102-311X2001000600002.

21. Spink MJP, Menegon VM. Práticas discursivas como estratégias de governamentalidade: A linguagem dos riscos em documentos de domínio público. In: Iñiguez L. Manual de Análise do Discurso em Ciências Sociais. Petrópolis: Vozes; 2004. p. 258-311.

22. Schwartzman R, Ross DG, Berube DM. Rhetoric and risk. Poroi [internet]. 2011; 7(1):9. Disponível em: https://doi.org/10.13008/2151-2957.1087.

23. Santo André. Anuário de Santo André 2014 [internet]. [acesso em 2019 out 1]. Disponível em: http://www. santoandre.sp.gov.br/pesquisa/ebooks/381435.PDF.

24. Medrado B, Spink MJP, Méllo RP. Diários como atuantes em nossas pesquisas: narrativas ficionais implicadas. In: Spink MJ, Brigagão J, Nascimento V, et al., organizadores. A produção de informação na pesquisa social: compartilhando ferramentas. Rio de Janeiro: Centro Edelstein de Pesquisas Sociais; 2014. p. 273-294.

25. Aragaki SS, Lima MLC, Pereira CCQ, et al. Entrevistas: negociando sentidos e coproduzindo versões de realidade. In: Spink MJ, Brigagão J, Nascimento V, et al., organizadores. A produção de informação na pesquisa social: compartilhando ferramentas. Rio de Janeiro: Centro Edelstein de Pesquisas Sociais; 2014. p. 57-72.

26. Nascimento VLV, Tavanti RM, Pereira CCQ. O uso de mapas dialógicos como recurso analítico em pesquisas científicas. In: Spink, MJ, Brigagão J, Nascimento V, et al., organizadores. A produção de informação na pesquisa social: compartilhando ferramentas. Rio de Janeiro: Centro Edelstein de Pesquisas Sociais; 2014. p. 247-272.

27. Davis MJ, French TN. Blaming Victims and Survivors: An Analysis of Post-Katrina Print News Coverage. Southern Commun. J. 2008; 73(3):243-257.

28. Zucker GS, Weiner B. Conservatism and perceptions of poverty: An attributional analysis. Journal of Ap- plied Social Psychology. 1993; 23(12):925-943.

29. Shildrick T, MacDonald R. Poverty talk: How People Experiencing Poverty Deny Their Poverty and Why They Blame ‘The Poor’. Sociol rev. 2013; 61(2):285-303.

30. Douglas M. Risk and Blame. Essays in Cultural Theory. Londres: Routledge; 1992.

31. Askman J, Nilsson O, Becker P. Why People Live in Flood-Prone Areas in Akuressa, Sri Lanka. Inter J. Disaster Risk Scienc. 2018; 9(2):143-156.

32. Righetto JM, Mendiondo EM, Righetto AM. Modelo de seguro para riscos hidrológicos. Rev. Bras. Recursos Hídricos. 2007; 12(2):107-113.

33. Graciosa MCP. Modelo de seguro para riscos hidrológicos com base em simulação hidráulico-hidrológica como ferramenta de gestão do risco de inundações. [tese]. São Carlos: Escola de Engenharia de São Carlos; 2010. 191 p.

34. Johnson M. Protection and Performance of Flooded Buildings. In: Lamond J, Booth C, Hammon F, et al., organizadores. Flood Hazards: impacts and responses for the Built Environment. London; New York: Boca Raton; CRC Press; 2012. p. 259-268.

35. Belk RW. Possessions and the Sense of Past. In: Russell Belk P, organizador. SV - Highways and Buyways: Naturalistic Research from the Consumer Behavior Odyssey. Utah: Association for Consumer Research; 1991. p. 114-130.

36. Spink MJP. Viver em área de risco: reflexões sobre vulnerabilidades socioambientais. São Paulo: EDUC; Terceiro Nome; 2018.

Recebido em 25/09/2019

Aprovado em 29/04/2020

Conflito de interesses: inexistente

Suporte financeiro: Silva SLA: Coordenação de Aperfeiçoamento

de Pessoal de Nível Superior (Capes); Martins MHM: Fundação

de Amparo à Pesquisa do Estado de São Paulo (Fapesp),

Processo no 2019/06595-2; e Spink MJP: Conselho Nacional

de Desenvolvimento Científico e Tecnológico (CNPq), Bolsa

produtividade nível 1A, Processo n 304602/2016-7 